\title{
Chapter 13 \\ Fathers on Leave Alone in Japan: The Lived Experiences of the Pioneers
}

\author{
Hideki Nakazato
}

\subsection{Introduction}

When the statutory parental leave scheme for the child's first year was implemented in Japan in 1992, it was designed to be gender neutral in the sense that both mothers and fathers were entitled to take leave. Despite this, and despite the subsequent amendments that were, at least in part, aimed at increasing fathers' take-up of the parental leave to which they were entitled, during 2012-2013 only $2.03 \%$ of all male employees whose spouses gave birth in the previous year have actually done so. While this level of take-up is much lower than that in most European countries, it has increased fourfold from $0.5 \%$ in 2005 and the proportion of fathers who took leave for 1 month or longer has also increased.

During the past decade, there have been some important changes in the parental leave scheme. Under the new scheme working parents are entitled to take leave and receive benefits even if their spouses are not working or are on leave. Furthermore, they get 2 bonus months of leave after their child becomes a year old if both parents take leave. Besides these changes, according to the Act on the Advancement of Measures to Support Raising Next-Generation Children (2003), employers were obliged to establish action plans to support balancing work and raising children.

The increasing, but very low level of fathers' take-up of parental leave in Japan raises two questions. Have policy changes contributed to this gradual increase? What prevents the majority of fathers in Japan from taking parental leave despite these policy changes?

The original version of this chapter was revised. An erratum to this chapter can be found at DOI 10.1007/978-3-319-42970-0_15

H. Nakazato $(\bowtie)$

Department of Sociology, Faculty of Letters, Konan University, Kobe, Japan

e-mail: nakazato@center.konan-u.ac.jp 
In this chapter, using interviews with fathers who took parental leave on their own in the changing policy environment of Japanese society, the author examines how recent improvements in policies affect fathers' negotiation processes in both their workplace and their family through a range of themes, including the factors which enable fathers to take leave alone and fathers' lived experiences of taking leave alone. It explores how these experiences affect both fathers' work and family life in a country where this phenomenon is very rare.

\subsection{Leave Policies in Japan}

Before the introduction of the gender-neutral parental leave scheme in 1992 the only statutory leave scheme related to birth and care of children was only unpaid maternity leave for 6 weeks before, and 8 weeks after birth. In the initial parental leave scheme, although both parents had the right to ask for a year's leave that included 8 weeks of post-natal maternity leave, employers were allowed, based on the collective agreement with their employees, to reject the request for leave by an employee whose partner was on leave or not working, unless it was during the 8 weeks immediately after the birth (the maternity leave period). Leave could be taken for a continuous period only, which meant fathers could not take leave when their partner returned to work after her parental leave if they (the fathers) had been on leave during the first 8 weeks.

Benefit payments by the statutory employment insurance were introduced in 1995 at $25 \%$ of an employee's average earnings before leave. Since the implementation of the statutory parental leave scheme, the period of basic leave entitlement after birth for a parent has been 12 months including maternity leave ( 8 weeks). However, frequent amendments were subsequently made in terms of benefit payment, conditions for special extension and eligibility, especially in relation to the other parent's employment status.

The leave policies during the period when the participants of this study were on leave were as follows: from 2005 (when Toru's wife gave birth to their first child) to March 2007, the eligibility criteria for parental leave were the same as those in place when the leave was implemented in 1992, when employers were allowed to reject the request for leave by an employee whose partner was on leave or not working unless it was during the 8 weeks after birth (the maternity leave period).

Benefit payment for maternity leave was $60 \%$ of previous earnings, and that for parental leave was $40 \%$. Parental leave benefit was an individual entitlement covered by employment insurance. Therefore, if an employer allowed an employee to take leave, the benefit was paid to the employee even if the other parent was on leave and was receiving benefit at the same time.

Leave and payment could be extended until a child was 18 months when (1) the child needed care for a period of 2 weeks or more because of injury, sickness, etc.; or (2) admission to a childcare centre has been requested but denied for the time being. 
Parental leave only applied to an individual employed on a fixed-term contract when they met all the following conditions: (1) they had been employed by the same employer for a continuous period of at least 1 year; (2) they were likely to be remain employed after the day on which their child reached 1 year of age, and (3) it was not obvious that they would finish the contract without an extension within 1 year after the child's first birthday.

In April 2007, the amount of the benefit was increased to two-thirds of previous earnings for maternity leave and to $50 \%$ for parental leave. Three years later, in April 2010, parental leave became an individual entitlement. From that date fathers could take leave regardless of the mother's situation. There was also a change in the number of leave periods permitted. From this time onwards, fathers could take a second period of parental leave even when they had taken parental leave during the first 8 weeks after birth.

A sharing bonus was also introduced. Under this scheme, leave could be extended until the child was 14 months old if both parents took leave, even though each parent was entitled to only 12 months after birth, including the maternity leave period. The objective of these changes was to increase fathers' leave-taking when the majority of mothers were at home or on leave until the child's first birthday. A newly introduced exemption from social insurance contributions increased compensation for the income loss during leave.

Although all fathers in this study had taken leave earlier, in April 2014, the benefit was increased to $67 \%$ for the first 6 months for each parent, which could be an incentive for fathers to take leave after the mother had taken leave for 6 months.

What characterises Japanese leave policies during the period under study, especially the period after 2010 , is the fact that the benefit payment became an individual right independent of a partner's employment status. The special extension to 18 months (subject to the conditions such as the non-availability of a childcare place) also needs attention as it enabled mothers to remain on leave until a childcare place became available, which could be a disincentive to fathers' taking leave. As Fig. 13.1 shows, there is an increase, with fluctuations, in the proportion of eligible fathers who took parental leave from the late 1990s to 2013 but the rate is still very low.

If we look at the duration of the leave by gender (Fig. 13.2) we see there is a big gap between fathers and mothers. Among the tiny proportion of fathers who took parental leave at all, very few (only one-quarter of $1.89 \%$, which is approximately $0.4 \%$ ), took 1 month or more. Mothers took obligatory maternity leave for 8 weeks after birth before they took the parental leave, which skews the contribution to the care of children by gender even more.

It should be also noted that around $70 \%$ of women who gave birth between 2005 and 2009 did not have a job at the time of the first birthday of their first child and another $17 \%$ took parental leave in addition to maternity leave, even though there has been steady increase in mothers who return to work after parental leave (National Institute of Population and Social Security Research 2011). 


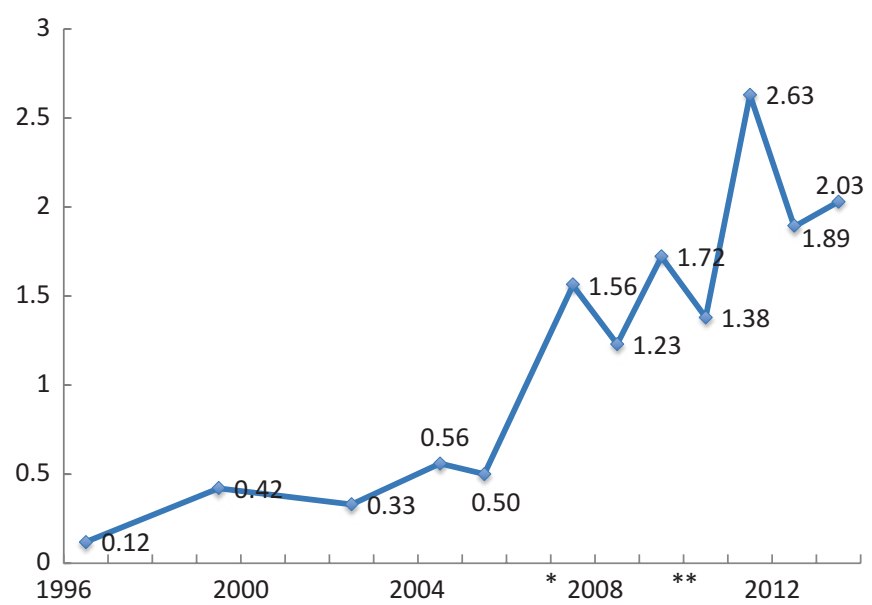

Fig. 13.1 Trends in the proportion of fathers taking parental leave $(* 2007$ : benefit $=50 \%$, $* * 2010$ : Entitlement as an individual; divisible into 2 periods, 2 month's bonus after child's first birthday when both parents take leave. Source: Ministry HLW 2014. Note: The result for 2011 is the national average excluding data for Iwate, Miyagi, and Fukushima Prefectures)

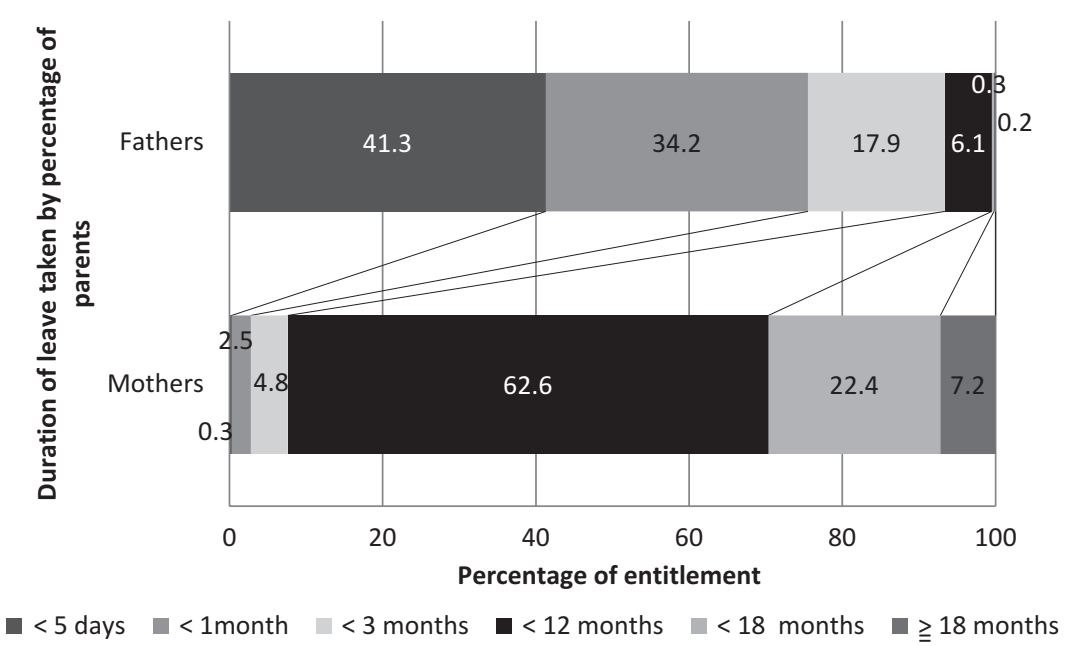

Fig. 13.2 Leave period taken by fathers and mothers (2012) (Source: Ministry HLW (2013) Office Survey Table 18(1) \& 18(2) (Recategorised). Note: Diagonal lines connect the borders of the same sets of categories between fathers and mothers) 


\subsection{Previous Research and Theoretical Approach}

\subsubsection{Why Fathers Do Not Take Parental Leave in Japan}

Most empirical studies on fathers' leave-taking in Japan focus on the reasons why fathers do not use parental leave. According to a large-scale national sample survey of 38,554 babies born in $2010,2 \%$ of fathers had taken, were on, or would take parental leave (Ministry of Health, Labour, and Welfare 2012). Approximately $40 \%$ of fathers who did not take parental leave said either that there was no provision for parental leave at their place of work, or did not know whether there was or not. Among fathers who knew about their leave entitlements and yet did not take leave, the reason that the largest proportion $(49.0 \%)$ chose is that the atmosphere and the situation at the workplace discourages fathers from taking leave. Twenty per cent chose the reason 'My wife is on leave' and $14.5 \%$ chose 'economic reasons'. It is important that the most frequent response was based on their lack of knowledge about their leave entitlement as most fathers are entitled to take leave if they are employed as permanent full-time workers (Ministry of Health, Labour, and Welfare 2012).

Similar reasons were also found in other studies (Matsuda 2012; Morita 2008; Sato and Takeishi 2004). Economic reasons are specifically related to anxiety about the impact on household income. This is explained by the large gender pay gap between fathers and mothers and insufficient leave benefit (Matsuda 2012). The workplace factors that discourage fathers from taking leave have been divided into three categories (Morita 2008; Sato and Takeishi 2004): (1) the atmosphere at workplace that discourages fathers from taking leave, (2) the men's anxiety about increasing the workload of their colleagues, (3) their anxiety about its impact on their own career.

The statement 'My wife is on leave' is not the same kind of reason as the others listed above. Mother's taking leave does not necessarily prevent fathers from doing so. This reason reflects a gendered view of childcare. The perception that childcare is the role of mothers is the reason that many fathers chose in another study (Morita 2008).

\subsubsection{Why Fathers Take Parental Leave in Japan}

Although there are fewer studies that focus on fathers who take parental leave, because of the scarcity of such fathers in Japan, some give us a valuable insight into fathers' experience of taking leave and the factors that enable them to do so (FujinoKakinami 2006; Morita 2011; Takeishi 2011). According to these studies, these enabling and encouraging factors are 
- expecting less economic damage because their wife is in most cases, working full-time (Fujino-Kakinami 2006).

- the father's intention to support the mother's return to work (Fujino-Kakinami 2006).

- efforts made at the workplace to cover the father's absence, such as providing a replacement and offering a telecommuting option (Fujino-Kakinami 2006).

- information has been provided at the workplace on job and family (Morita 2011).

- the manager's encouraging attitude (Morita 2011).

- the father's and his partner's positive attitude towards sharing housework and childcare because of dual earning (Fujino-Kakinami 2006).

According to Takeishi's (2011) study, which used a survey and interviews about workplaces where some male employees took parental leave, personal factors had more impact on their decision to take leave than environmental factors in the workplace, such as the provisions of replacement employees and the workload level. These factors include a strong desire in the male employees to take leave, their understanding its value, earlier discussions they had had with their wives about leave-taking, and their preparation for the loss of household income. However, in the interviews, the fathers who took parental leave also show the importance of having an understanding atmosphere in the workplace, such as needing to do little overtime, managers' understanding of this leave entitlement, cooperative attitudes among other workers, a clear range of job roles and necessary knowledge and skills, and an announcement of support for parental leave by the whole company.

Other findings derived from studies on fathers who have taken parental leave include its effects on themselves, their family relations and their workplace (FujinoKakinami 2006; Morita 2011). According to these studies, the fathers expressed positive views on their experience during the leave. They recognised the hardship of working mothers, experienced changes in their view on work and life, and gender roles, and developed an effective work style (to avoid overtime so they could be more involved in the care of their child and housework) within a limited time. Some of them developed social connections outside the workplace.

The studies examined here seem to have focused on the most common experiences of fathers who take parental leave. Looking at studies in countries where a relatively large proportion of fathers take parental leave suggests, however, that there is a diversity of experiences.

\subsubsection{Theoretical Framework and International Context}

As well as the interest that these studies on Japanese fathers have generated in this research, the present study follows the theoretical framework described in the introduction of this book. It draws on different approaches including family and parenting studies, gender studies and social policy, which are not a prominent focus in Japanese scholarship. In particular, comparisons will be drawn with Wall's (2014) 
Portuguese study and her emergent profile typology. The four profiles range from 'supported (helpers)' who are strongly supported both by a partner and a third party, to 'innovation and deconstruction'; those who, before taking leave, were already regularly involved in housework and childcare, then became fully involved caregivers, and reflect the impact of leave on gender roles. The study revealed the diversity of fathers' experiences of taking leave alone. In Portugal as in Japan, the proportion of fathers who took parental leave was very low but rapidly increased after the implementation of a new leave policy. It is valuable to discern whether there may be a similar variation among Japanese fathers who took parental leave alone.

\subsection{Methods}

\subsubsection{Research Questions}

Based on findings from Japanese research and the common goals of the Fathers on Leave Alone Project, I set up a number of research questions.

The first major research question was what characterises the fathers' motivations and decisions to take parental leave in Japan, a country where this practice is very rare. This includes asking how the fathers were able to

- overcome the fear of income reduction

- negotiate the common perception that the care of the children (or at least taking parental leave) is the mothers' role

- cope with the fear of negative reaction from their workplaces

- deal with the anxiety about imposing increased workloads on their colleagues?

The second major research question was an attempt to obtain their reflections on taking leave and the lived experience of fathers who took leave alone. The third question was whether fathers' leave take-up contributed to the couples seeking equal career opportunities.

\section{Sampling Criteria}

Following the sampling criteria for the Father on Leave Alone Project, this study recruited fathers who took parental leave alone for at least 1 month with a child who was under 3 years old. As anticipated from the statistics showing the scarcity of Japanese fathers who took parental leave for more than a month, finding fathers who also met the project's sampling criteria was difficult. Two were recruited through acquaintances. Snowball sampling was also adopted. I asked participants and my other acquaintances to introduce me to someone who appeared to meet the criteria. Although I was given contacts for more than ten fathers who took parental leave, closer investigation revealed that in actuality some of them took leave for shorter 
periods or had done so with their partner. From February to September 2014, six fathers who met the criteria agreed to be interviewed, although another father who also met the criteria was reluctant to participate due to possible negative consequences at his workplace.

Considering the limitation of time for the interviews, which were to be conducted by one researcher, I tried various pathways to reach participants to avoid collecting data only on fathers with similar profile. Table 13.1 describes the profiles of the interviewees and their partners at the time of leave. All the fathers are university graduates, but the mothers educational level varied from that of high school graduate to holders of a master's degree. The fathers are employed in a large multinational corporation, a small IT company, the public sector, a university and a pharmacy. All have two children, but five of them took parental leave for one child only. They were in their 30 s or early 40 s at the time of the interview. When they took parental leave, four of them were 35 years of age or older and two were in their late twenties.

In order to visually compare careers and leave take-up patterns between partners and across couples, I have created a chart with different horizontal lines representing work situations and leave take-up for each of the partners (Fig. 13.3).

\section{Interviews}

Semi-structured interviews with the six fathers were conducted according to the guidelines of the Fathers on Leave Alone Project at the researcher's office (a singleoccupied room) or a café. The interviews lasted 2 to 3 hours and were taped. Notes were also taken over the course of the interviews.

Core questions included:

- interviewee and family profile (including occupations, working hours, commuting hours, duration of marriage, age of family members.)

- timing and duration of leave for fathers and mothers

- process of deciding to take leave

- reactions to and comments about taking leave alone

- fathering and mothering during the first days/weeks after birth

- fathering during leave alone (good or bad things, major difficulties, negative or positive feelings over the day)

- impact of leave take-up on different domains of life (relationship with the partner and children, work)

- going back to work and organising childcare after leave

- balancing work and family life today

- perception of differences between fathers and mothers 


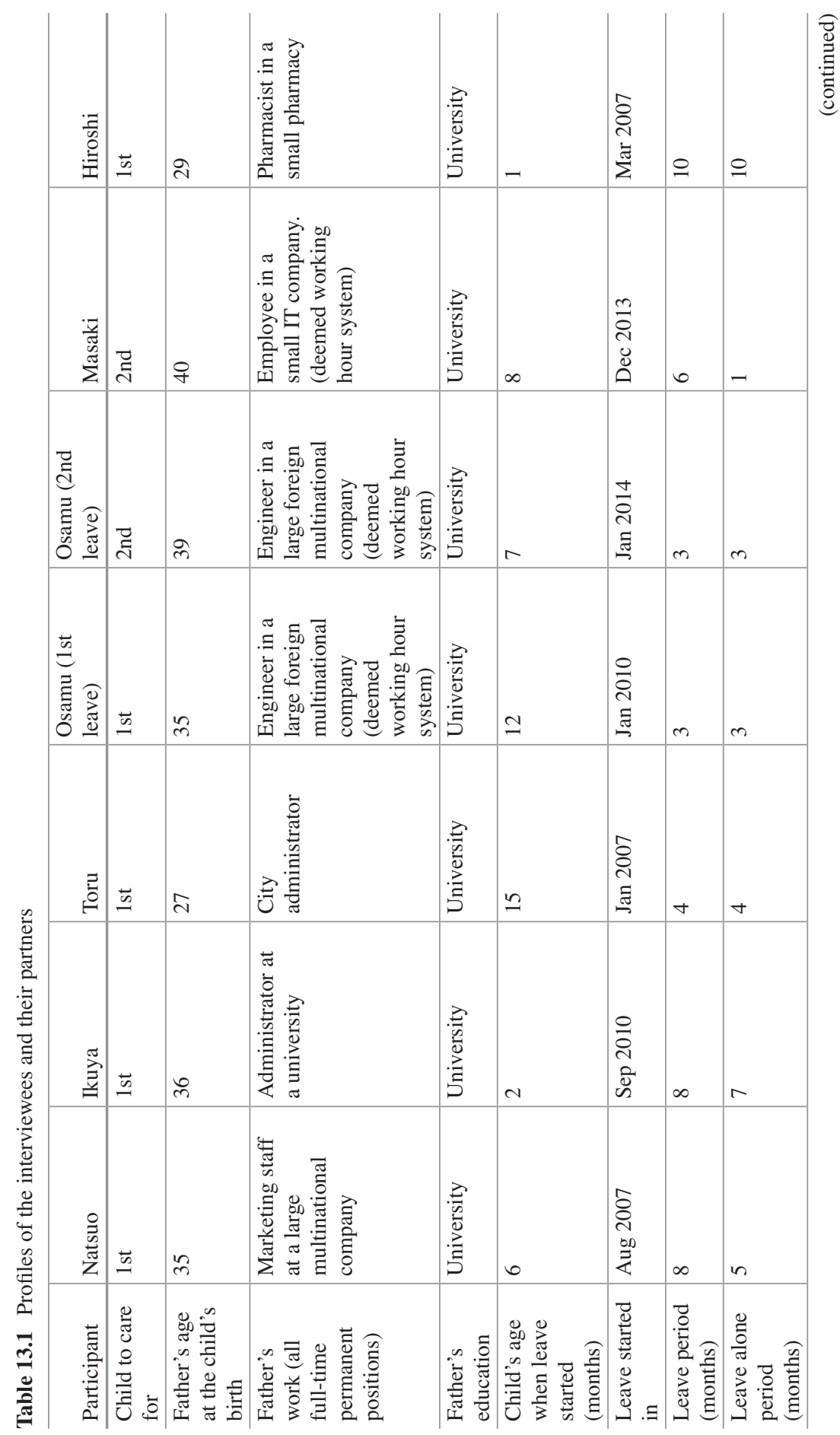




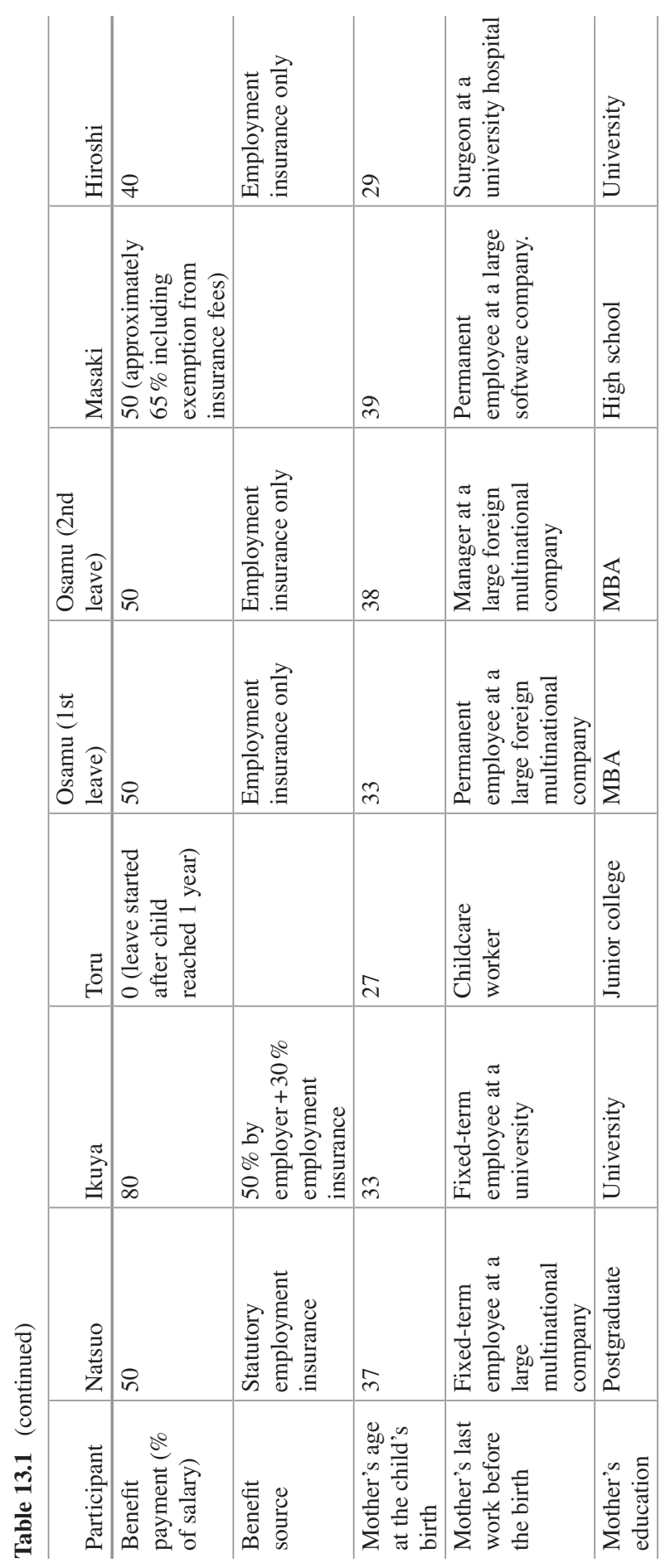




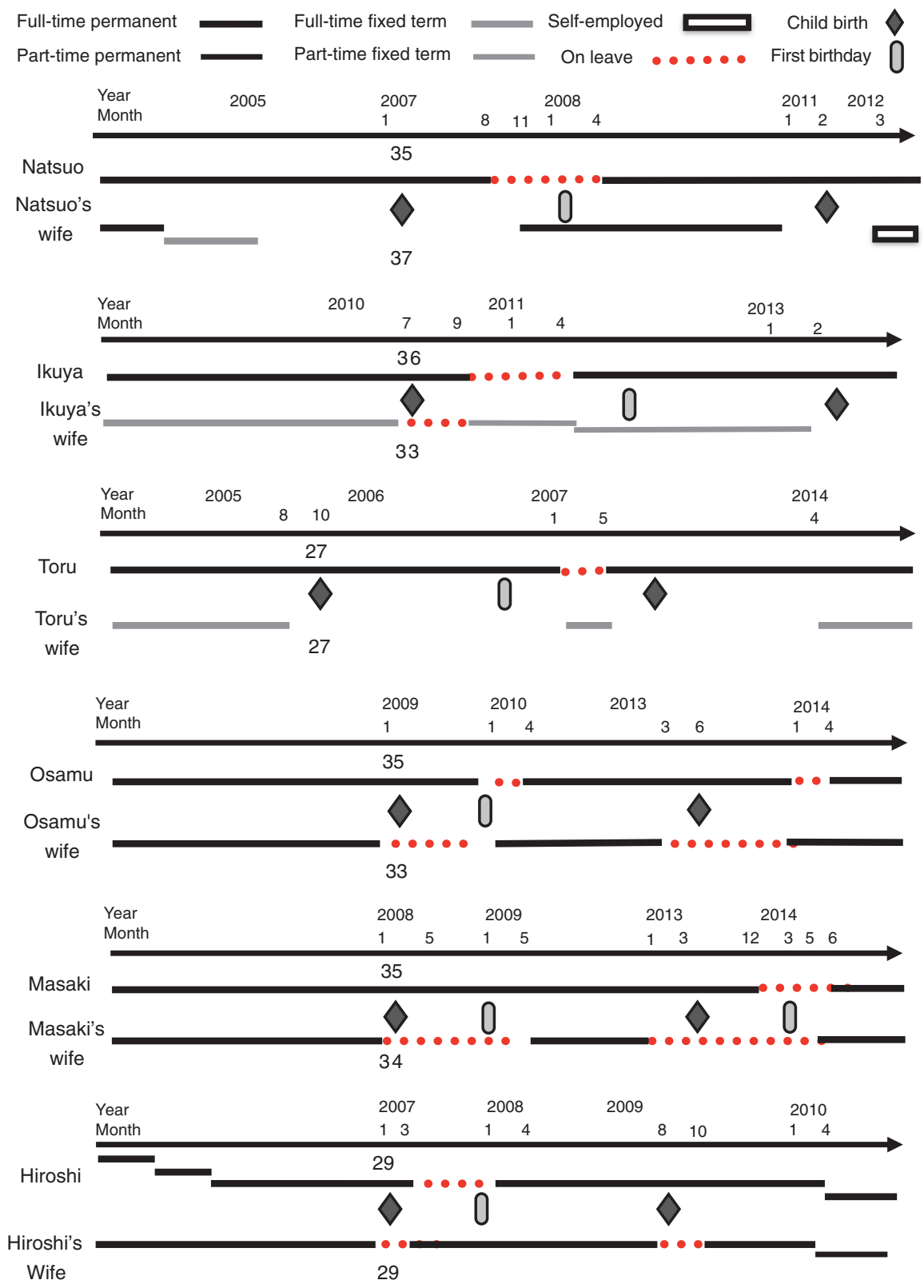

Fig. 13.3 Characteristics and leave take-up patterns of the participants and their wives (Notes: Stepped lines denote "job changes". Blanks between lines denote "unemployed". Numbers near the symbols for the child birth denote the ages of the father and mother at the birth) 


\section{Coding and Analysis}

The parts of the interviews related to the research questions were transcribed. The transcribed responses were coded with the assistance of NVivo, a qualitative analysis software program. Coding methods were partly deductive and partly inductive. We first set up nodes based on the research questions and core questions. Within each predefined node, we created sub-nodes that represent the different types of responses. For example, we set up a node on negative feeling and a sub-node on isolation beforehand, and added sub-nodes such as bored or irritated in the category of negative feelings inductively after reading the transcript.

\subsection{Reasons for Taking Leave}

We start by examining the motivations and reasons given by fathers taking parental leave in Japan. All the fathers interviewed were able to clearly explain why they took parental leave. In the previous detailed studies mentioned above, fathers took parental leave to support their wife's return to work after her leave or decision to stop working in order to care for their child (Fujino-Kakinami 2006). However, for the participants of the current study, their wife's work situation was not necessarily the reason for taking leave. One group of fathers took leave because of their wife's need to return to work (Ikuya, Osamu, Hiroshi), and another group of fathers took leave for other reasons (Natsuo, Toru, Masaki).

\subsubsection{Taking Leave to Support the Mother's Return to Work}

Three of the participants (Ikuya, Osamu, Hiroshi) explained that they started to consider the possibility of taking leave in order to enable their wife's early return to work. Although two of them had wives who worked as full-time and permanent employees, Ikuya's wife was in a fixed-term position that was going to be terminated before her child's first birthday so she was not entitled to parental leave. This made for a different situation:

\footnotetext{
The possible options were to quit the job and become a stay-at-home mum, or to return to work after the two-month maternity leave by putting our child in daycare. The first option was not acceptable as she did not want to quit and her employer asked her to return after two months if possible.... So we took the other option and checked whether there was a daycare place or a pre-school for a child of two months old, but we couldn't find one. There was little information about baby sitters, either. Then we came up with the idea the fathers can take parental leave, can't they? I started looking for the leave provision at my workplace and found it. (Ikuya)
}

The other two fathers also started searching for information about their entitlements when they decided to take leave because their wife needed to return to work before the child was able to go to daycare. 


\subsubsection{Taking Leave for Other Reasons}

The three other fathers took leave for several different reasons, including the child's best interest and the fact that they wanted to spend time with the child.

Natsuo's wife was not working when they had their first child in 2007 (even though she was expecting to go back to work), and he wanted to take leave because he had learned from a book that the time a parent spends with a child is important. 'It sounded interesting to take leave as none of my other male colleagues had done so' (Natsuo). Under the statutory leave system at that point employers were able to limit the leave taken by employees whose partner was on leave or not working. However, the company Natsuo worked for provided leave entitlements beyond the statutory system, which enabled him to take leave even though his wife was not working. Although he started leave when his wife was at home, Natsuo took leave alone for 5 months as she started searching for jobs and found one after Natsuo started his leave.

Toru wanted to take leave and asked his wife to find a job (a condition for him to take leave) because he knew fathers could do this and thought 'Why shouldn't I, even if other fathers don't?' Masaki did not take leave for his first child. At the time his second child was born in 2010 he was not satisfied with his situation at the workplace and was considering whether he should continue working there. His wife suggested he took leave instead of quitting. He agreed but asked his wife to continue her leave. So he was on leave with his wife for 5 months and then on leave alone for a month when his wife returned to work and his child started daycare. Because of the amendment of the statutory leave system in 2010, he was entitled to leave even if his wife continued her leave.

\subsection{Coping with Common Obstacles}

Existing evidence suggests that there is a range of common obstacles hindering Japanese fathers' leave-taking, including financial obstacles and those relating to the workplace or to cultural factors (Matsuda 2012; Morita 2008; Sato and Takeishi 2004). In this section we examine how our sample of fathers negotiated these constraints.

\subsubsection{Reduction of Income}

The first question we should ask is how these fathers coped with the income reduction that resulted from their taking leave. In two cases (Osamu and Hiroshi), their wife was working full-time with an income comparable to their husband's, and they did not have to worry much about the economic impact of the father's taking leave. In other cases, the mothers did not necessarily earn the same amount as their 
husbands, or they were on leave or not working at the time. Except in the case of Toru, long dual-earner careers before the birth of the first child seem to have helped them reduce economic damage. Natsuo, Ikuya and Masaki had their first child when they were in their mid-thirties:

Well, we had been a dual-earner couple until the birth of the child, and we expected my wife would start working again. Otherwise, we would be worried about the loss of income. (Natsuo)

Toru is the only participant who received no leave benefit payment, and his wife was not working at the birth of their first child. However, he calculated the savings they would have to make and also considered the income of his wife, who would be working part-time while he was on leave, so he saved the necessary amount before his leave started.

\subsubsection{Getting Information About Leave Entitlement}

As we already know from previous research, lack of knowledge about their own entitlements is a major reason for fathers not to take parental leave. How did the fathers in the current study learn about their entitlements? Three fathers who decided to take leave to support their wife's return to work started searching for information about parental leave in books or on the internet and intranets.

Among the other fathers, two (Natsuo and Toru) were interested in the role of fathers in the care of young children and decided to take leave spontaneously and therefore started searching for detailed information about leave entitlements. Even when his second child was born, Masaki did not know it was possible for fathers to take parental leave, but about 6 months later he read an internet article about the new entitlement for fathers to take leave even when their wife was at home to take care of their child, and he talked about it with his wife. This situation might have led her to suggest to Masaki that he should take leave when she saw he was dissatisfied with his work.

\subsubsection{Moving on from Perceptions of Mothers as Primary Carers}

Although three fathers were urged by their wives' needs to find someone to take care of their children, taking leave would not have been an option if both or either of the parents had believed that childcare was the mothers' role alone or that it was impossible for fathers to take over the role of primary carer. Moreover, the other three volunteered to take leave. How were they able to avoid the gendered perception of their roles?

The participants were not confident about taking care of their child. Some of the mothers were more or less worried about their husband's care role. What all couples 
had in common, however, was that they had been sharing housework before the birth of the child. Ikuya and Osamu would cook regularly. In the other four cases, although wives had taken the main role in cooking, the fathers were taking at least some part regularly or had experiences of regular housework, such as cooking on weekends, helping with food preparation or cooking regularly before marriage. According to the National Survey on the Family 2008 (Nishioka et al. 2012) only $20 \%$ of married women whose youngest child was under 1 year old had husbands who cooked once or more per week, so cooking could have been an obstacle to fathers' taking leave in most families. It is possible to assume that the fathers interviewed had an advantage over average Japanese fathers in that they could manage housework alone.

It should also be noted that, from the fathers' point of view, none of the wives were traditional homemakers. According to the participants, their wives did not worry about their husband taking leave.

Q: What was your wife's reaction?

Natsuo: Nothing special, I mean, she said, like, 'OK'.

Q: $\quad$ No surprise?

Natsuo: Well, No.

Q: $\quad$ No pleasure? No opposition?

Natsuo: That's right.

Q: $\quad$ Did she know that fathers could take parental leave?

Natsuo: Yes, yes, maybe she did. She likes gender studies and feminism.

Hiroshi's wife worried about his stress from taking care of their child alone, but did not stick to traditional gender roles:

She thinks we should do what we can do. She is working [as a medical doctor] at the place where they had to do things regardless of their gender, so she did not think 'Men should do this, women should do that'. (Hiroshi)

Although the fathers were not very confident about their role as a primary caregiver, their housework experiences and their own and their wives' attitudes that were relatively free from traditional gender role stereotypes seem to have helped them take leave alone.

\subsubsection{Fear of Negative Workplace Attitudes}

According to existing studies (Morita 2008; Sato and Takeishi 2004), apart from the lack of knowledge about their entitlement, emotional barriers such as a discouraging atmosphere at work is the largest reason why fathers do not take parental leave. The role of managers in encouraging or hindering parental leave uptake has been shown to be a crucial factor and this was explored in this study.

For three fathers (Natsuo, Ikuya, Toru), managers were supportive from the time they first raised the issue, although Natsuo's manager told him later that he originally thought he was joking. Although their occupations varied from that of sales 
staff at a multinational corporation to a university administrator and a public sector employee, they all referred to their manager' personality as a factor in their responses to the request to take leave.

The other three fathers did not get approval for their requests immediately and needed further explanations or negotiations. In two cases, it was only a matter of information that was needed. Masaki's manager did not know that both parents may take leave at the same time, but after Masaki explained the position and sent him some information about the changes implemented that year to the scheme, the manager said it was $\mathrm{OK}$ if the law provided for it. There was an atmosphere conducive to allowing long leave because the company employed many international staff who wanted to take leave to visit their home country and many female employees who liked travelling overseas. When Osamu told his manager about his plan to take leave, he reported that the manager held his head in his hands as the timing was not convenient for the company, which was undergoing restructuring. Apparently the manager had no idea about the legal entitlement for fathers to take parental leave and asked for time to consider. After a month of information seeking, he reported back that he now understood that employers were legally unable to reject requests by fathers for parental leave and offered to suspend Osamu's post for 3 months until he returned.

Hiroshi was in a more difficult situation. His manager was surprised when Hiroshi told him about his plan and intimated that he could not guarantee that Hiroshi would be able to return to his job if a replacement had been employed on a permanent basis.

In summary, while three workplaces facilitated leave-taking by fathers, the other three presented more constraining environments. In the case of Hiroshi, there was even a threat of job loss and fear it would have a negative impact on his career. However, in the area where he lived, his qualification as a pharmacist virtually guaranteed that he would be able to find a replacement job. Moreover, in the case of this couple the high income of Hiroshi's wife helped his decision. What the six fathers did have in common was that they had all made strategic preparations before asking for parental leave from their managers. It appears that the informants had much more knowledge about their formal leave entitlements than their managers.

\subsubsection{Impact on Colleagues' Workload}

Anxiety about imposing additional workloads upon their colleagues is also known to be an obstacle to fathers taking leave. Having replacement employees would reduce this anxiety. Was this the case with the fathers in our study? Among six fathers, however, only two (Natsuo and Hiroshi) had the comfort of knowing there would be a replacement for them at work during their leave. How did the other fathers cope with the anxiety about the impact on their colleagues' workloads?

For the cases where leave period was relatively short (Toru and Osamu), the fathers were able to suspend most of their tasks until they returned, although they asked their colleagues to take on part of their tasks. For those who took longer leave 
without replacement, collective support at the workplace helped. Masaki emphasised that the ongoing transition of work styles, in which employees work more as a team and nobody is given tasks that can be done only by themselves, made it easier to hand over their tasks to their colleagues. Ikuya worried about the inconvenience he would cause but he knew his colleagues (including the junior ones) would compensate for his absence and his manager assured him that she would be able to handle it.

Although having a replacement employee decreases the father's sense of guilt, it can increase the risk of losing his position to return, although it is illegal for the company to dismiss or transfer an employee who has taken leave. Hiroshi accepted his manager's suggestion about recruiting and employing a permanent replacement, which meant there was the possibility that he would lose the position to which he hoped to return.

\subsection{Lived Experience of Fathers Who Took Leave Alone and Its Effects}

So far, we have explored the processes through which fathers obtained their leave alone status. In this section the lived experience of their leave and its effects on their later work and personal lives will be examined, with a particular focus on common and diverse features.

\subsubsection{Housework and Care During Leave}

Five of six fathers can be described as fully involved caregivers during some part of the leave alone periods and did all kinds of care and housework except for breastfeeding. None of the fathers received regular support from their own parents. Masaki had a somewhat different experience from the other five. His son would normally go to a childcare centre during the period when he took leave alone. However, despite that, Masaki actually had to care for his son alone all day as the child fell sick for a week during the period.

Ikuya describe his typical day, going for a walk holding his daughter in the morning and the afternoon, feeding her milk and cooking, as follows:

Ikuya: It was the hot season in August and September. I would go for a walk holding my baby early in the morning. That was after my wife left home and I would feed her milk or we would go out together when my wife was away at work. After coming back I got her to sleep or fed her in an air-conditioned room. Then I would go for a walk again when it got cooler in the late afternoon. For breakfast I just ate some bread, and had some leftovers or quick meal for lunch. For dinner, I would cook one or two dishes before my wife came home as long as I had the time. While my wife breastfed our daughter and put her to bed, I would prepare the meals for the next day. I took picture of these and put them on the blog or tweeted them. 
Q: $\quad$ What was the proportion of the share of cooking?

Ikuya: Well, fifty-fifty; actually, I did 60 to $70 \%$. My wife would cook after she came home. Shopping at a supermarket on her way back was her role, and sometimes she cooked quickly or she told me to cook what she bought. We share our recipes, which expanded our cooking repertoire.

Toru also did all things necessary to care for a small child including cooking most of the meals:

Q: $\quad$ Were you preparing the baby food at that time?

Toru: Yes, I cooked it soft, cut into small pieces and so on.

Q: $\quad$ Was it a different experience to do all these things including preparing meals for very young children while you were on leave, even though you had cooked before?

Toru: Yes, but I myself said I wanted to do it. I felt I would do my best if it is for a limited time and there would be only be a relatively short experience. A fifteen-month-old boy cannot eat by himself, so I had to feed him, while I was eating or doing something else.

The case where the mother was working the longest hours was Osamu's. He spent nearly $12 \mathrm{~h}$ per day alone with his child immediately after the mother returned to work. He would struggle to do housework while dealing with a child crying almost all day.

Although Masaki felt as if he was just on holiday during the first week of his leave together with his wife, he changed his attitude after his wife asked him what he was on leave for. They agreed that cooking was his role even during the period of leave which they spend together and had a hard time thinking about preparing a variety of different meals every day.

\subsubsection{Emotional Experiences}

In this section fathers' accounts of their mental and emotional experiences will be examined. Although an existing study emphasises fathers' positive evaluation of their leave experiences (Fujino-Kakinami 2006), many of the fathers in the current study talk about the difficulties they experienced, and four of the five fathers who took leave for the first child did not do so for their second child. Natsuo reflects that parents should not take care of their child on their own without help from their partner.

Most fathers experienced isolation or feeling impatient waiting for their wife's return home, even though in most cases their wife did not work overtime and in some cases they worked reduced hours. This isolation seems to be partly related to the difficulties for fathers to find another man in a similar situation, given the small proportion of fathers who take parental leave in Japan:

I couldn't make a 'mother friend', and didn't have courage to get into mums' circles. All I was able to do was to talk to my child. I realised how isolated a stay-at-home mum would be. I attended a couple of events for children, but there were only mothers there. Well, I felt very hesitant about going to those kinds of events. They would look at me wondering what I was doing, so I could not go very often. (Toru) 


\subsubsection{Busy and Bored}

Fathers on leave alone experienced feeling busy or bored, or on occasions, both. One father contrasted his leave alone experience with the experience of taking leave with his wife:

Q: $\quad$ Do you remember what your life was like?

Natsuo: While I was on leave alone? Well, you know, it was monotonous.... When I was on leave with my wife I thought there was too much time and there was no need to take leave together. Too many hands. After getting leave on my own, I had no time, only an hour or so, for instance, to surf on the internet. I think I was irritated. When I put my son down, he would start crying, so when I tried to get him to nap, I would hold him on the sofa and fall asleep with him. I was bored, yes, bored.

Another father recalled how busy he had been when his child was sick:

The hardest time was when my child was sick. I had to do all the housework alone, but since I had to keep an eye on my child, I had to be in the living room except when he was sleeping, during which time I put the laundry in and out for drying and cooked quickly. I felt I was extremely short of time, and had to do things on my own. (Masaki)

\subsubsection{Feelings of Responsibility for a 'Fragile Infant'}

Some of the fathers described their fear resulting from the heavy responsibility of caring for a child:

The hardest thing was that she wouldn't accept bottled milk when I started caring for her alone. She would accept the bottle from my wife, and loved to be breastfed when my wife came back from work, so I felt a sense of failure and was at a loss as to what to do. But then she suddenly started to drink when I slightly changed the way I held the bottle.... I had been wondering if she was going to lose weight, or whether she just didn't want to be fed by a man's hands until I found a right way to make it feel right. I really felt anxious when it wasn't going well at first. (Ikuya)

The largest difference [from the period before my leave] was that there was a strong pressure that there was no one to take care of her if I didn't do it. She was so small that I was afraid that at the worst, she might even die if I failed in some way. So for quite some time I continually experienced a vague feeling of anxiety. (Osamu)

\subsubsection{Positive Feelings}

The fathers' experiences were not always of hardship, although in this sample reports of difficulties and stress predominated. In their accounts fathers also recalled pleasant experiences; in particular, walking around with their child and watching 
the child learning to do what he/she had not been able to do - to observe the growth and development of their child:

After my first daughter got used to the situation [with her mother working], I was happy with the life on leave, to be honest. When I work, it was hectic every day and full of stress, but I was away from it, if only temporarily, so I spent a very pleasant time in that sense.... Going out for a walk after lunch, that was almost impossible when I'm working. (Osamu)

\subsubsection{Strategies for Coping with Negative Feelings and Stress}

There is one case with much less description of isolation or stress than others. It seems that Hiroshi did not experience these emotions because of his very exceptional resources. He had a male friend who had already started taking care of a child while he worked at home as a programmer and his wife was working as a full-time surgeon. His parents sometimes visited to see their only grandchild. In addition, he started to use a crèche (3-4 h for 2 days/week) from the middle of his leave period. He attributed his relatively lower level of stress partly to the fact he had kept cats from the time before the birth of the child. He was able to continue talking to someone other than the baby. This helped him to become accustomed to a living thing with a will of its own, which was sometimes difficult to control, before the birth of his child.

It should be also noted that three of other fathers used blogs or social networking services to share their experience with other people and that seems to have compensated for their lack of communication with adults face to face.

\subsubsection{Effects of Taking Leave on Their Own}

What effects did taking leave on their own have on fathers? From the family point of view, all the fathers said they understood how hard it must be to be stay-at-home mum, and they came to think of childcare and housework as their own responsibilities:

\footnotetext{
What I thought recently is that parental leave is not so much for the child, but more for the partner. There are bigger effects for the partner: sharing the difficulties and the feelings related to them. I found that there are a lot of things you cannot know about until you actually do them. I hadn't recognised how hard it would be to prepare every meal before I took on that role. There is endless housework for 356 days a year, which produces nothing. That is very painful. By learning about it by experience, I was able to become more considerate to my partner, and came to support her spontaneously after my leave ended. (Masaki)
}

The way housework and childcare was divided up after the fathers returned to work varied across the participants and it seems to depend on agreement between the partner, taking account of the balance of priorities in their occupational careers. The fathers whose wives were career oriented, such as Natsuo, Osamu and Hiroshi 
seemed to share housework and childcare almost equally with their wives. Nevertheless, even fathers whose wives worked part-time or were not working continued to share housework to some degree; for example, cooking regularly on weekends even after they returned to work.

In terms of the relationship with his children, only one father sees a clear difference between the child for whom he took leave and the child for whom he did not. Toru sees the elder child as more attached to him while the second child is more attached to his wife. He reflected: 'It might be just a coincidence, or the time we spent together during leave might have built mutual trust. It was an important experience'. Even though other fathers did not mention clear differences in their relationships with their children, they describe having a closer relationship with their children overall compared with other fathers.

In addition to the effects on their family relationships, the experience of taking parental leave on their own also affected the fathers' work. Three fathers said that they learned to work efficiently and to utilise fragmented pieces of time, and two of them changed their way of working so they did not have to work overtime. Three fathers have taken on the role of picking up their children at the childcare centre, which is more of a mothers' role in Japan, as it requires leaving their workplace without doing overtime.

Other effects on the fathers' work include a deeper understanding of co-workers and clients and a new appointment to an important position. Toru was assigned to the section in charge of early childhood education and care. Although it was hard for Hiroshi to catch up on the up-to-date professional information he had missed during his 10-month leave, he came to understand the situation of clients (mothers) who are taking care of sick children.

In addition to the effects the experience had on the fathers themselves, three noticed effects on their workplace. Natsuo as a manager made his section overtimefree, and another two noticed colleagues made changes in their working hours.

\subsection{Does Fathers' Leave-Taking Contribute to Equal Career Opportunities Between Couples?}

Here I will address the last major research question: whether fathers' take-up of leave promotes equal career opportunities between partners. Figure 13.3 clearly illustrates there is both continuity and breaks in the occupational careers of all the couples who participated in the study.

As we saw earlier, in three cases (Ikuya, Osamu, Hiroshi), fathers took leave prompted by the necessities relating to their wife's work situation. In other cases, the fathers took leave for other reasons such as their interest in the care of the child or the necessity to take a break from work. However, these differences do not seem to have affected the equality of career opportunities between the partners. In two cases, Osamu's wife and Masaki's wife had continued working in the same com- 
pany at the time of the interview, and the reasons why the fathers took leave differed. Osamu explained his intention to support his wife's career:

Q:

Whose idea was your taking leave? What did you and your wife discuss?

Osamu: Well, it was mine, I think. She would have been on leave for 1 year, and when I heard her plan to return to work afterward, I thought I should support her and take leave if I was to consider her career.

Osamu was the only one of all the fathers in the current study who took parental leave twice. On the contrary, the aim of Masaki's taking leave was not to support his wife's career. However, both resulted in the continuity of the mothers' work, even though the mothers took longer leave than the fathers in both cases.

The other four mothers either changed their employers or had quit their jobs by the time of the interviews. This does not necessarily mean that they prioritised their husbands' careers over their own. In the cases of Ikuya and Hiroshi, where the fathers took leave to help the mothers continue their jobs, it is clear that father' taking leave promotes the continuity of the mothers' career as she had only a short leave period ( 8 weeks in both cases). However, this short period might have made the mothers decide to take a break from work after the birth of their second child. Hiroshi's wife continued working at the same university hospital even after she gave birth to her second child, but then moved to work at another hospital where she could reduce her working hours. She thought it would be too hard for her to continue working full-time at the university hospital, and wanted to move to the city where her parents lived and where she had more friends. Hiroshi looked for a new job there, and found one in which he was allowed more flexibility, and then he quit his job at the pharmacy. It could be said that he decided to change his job to help establish an environment conducive to finding a better balance between work and life for both himself and his wife.

In two cases (Natsuo and Toru) the mothers were not working when the fathers decided to take leave. What impacts did the fathers taking leave have on the career opportunity of the mothers in these cases? Although from Fig. 13.3 Natsuo's wife does not appear to have continued her career, she has been working with relatively short breaks and has now established her own firm as a self-employed professional. She was not working at the birth of first child because she had to quit her job when her husband was transferred overseas. However, she found another job 10 months after the birth of her first child. By taking leave Natsuo definitely helped her in her search for jobs.

Toru's wife quit her job as a childcare worker, but started working on a 4-month contract when their first child was 15 months old, as Toru wanted to take parental leave and his wife needed to be working. She planned to return to work as a childcare worker when the younger child enter preschool, but taking him to and picking him up from preschool made it difficult and she had to wait until he entered primary school and she start working part-time as a childcare worker. Although Toru's taking leave did not promote his wife's continuous career, that experience and his commitment to housework and childcare seem to have made it easier for his wife to work when her children were still young. 
Figure 13.3 depicts inequality in the continuation of career by gender. However, given the strong gender stereotype that the mother is the primary carer and the resulting low labour force participation of mothers with small children (see Sect. 13.2) in Japan, it is likely that the taking leave of the fathers in this study helped their partners continue their career or return to work with a relatively short break. In-depth interviews revealed that most participants are very concerned about their partners' career.

\subsection{Discussion and Conclusion}

A major focus of this chapter has been an exploration of the factors that enable or encourage Japanese fathers to take parental leave as in the Japanese context this phenomenon is very rare.

Moreover, the sampling criteria for this study were strict in that the participants had to be fathers who had taken leave for a month or more and done so on their own. Given these tough criteria, it was expected that the fathers would have needed to take leave so their wives could return to work. However, we found that half of the fathers interviewed did not face such imperatives, but took leave on their own for other reasons including the child's best interest, their wish to spend time with the child, and their need to take a break from work.

As for the factors that lead to taking leave, those described in existing studies (Fujino-Kakinami 2006; Morita 2011; Takeishi 2011), such as reduced economic stress because the parents were dual earners, the presence of supportive managers and colleagues, and a strong desire to do so in the fathers themselves, were found in this study. However, it was also found that these conditions were not always met. What all fathers had in common was a flexible attitude to gender roles and respect for the career of their partner. The mothers' attitudes to gender roles and fathers' taking leave also helped them take a decision that is uncommon in Japan. Moreover, the recent policy change appears to have increased the possibility for fathers to take leave in Japan.

The lived experiences of the fathers were also examined closely. They became significant carers and did a larger share of housework during the period they were on leave on their own. Most of the fathers describe their difficult experiences in considerable detail, confessing to feeling isolated, busy and bored during leave. However, they also recalled some pleasant experiences, which were described as something that would have been impossible to have when they were working. Although they were sharing the housework and were committed to the care of the child even before their leave, their experience of leave alone seems to have had a great impact on their perceptions of childcare and housework, which they came to think of as their own responsibility. This change in perception affects both their family relationships and work, and some of them actually changed their work style.

If we take a closer look at the data, we can understand that equal career opportunities between couples should be examined in the context of a life course perspective. Although taking leave on their own by fathers might not necessarily appear to 
contribute to the continuation of their partner's employment, it seems to have expanded their career opportunities as most of them kept working with relatively short breaks, at least by the standards of Japanese mothers. The evidence shows that most of the fathers kept working for the same employer regardless of the births of their children, and only one father took leave twice.

Despite the policy changes aiming at promoting fathers' leave take-up, mixed conditions in Japanese society seem to have weakened the incentive for fathers take parental leave. These conditions include the early use of crèche, the generous entitlement to leave and an atmosphere conducive to using it; especially for mothers, together with a persistently prevailing life-course option for women to quit their job after childbirth and the difficulties for fathers to establish support networks. Nevertheless, by taking parental leave, even if it was only for one child, the fathers in this study seem to have expanded the career opportunity for the mothers through the fathers' greater involvement in childcare and housework compared with average fathers in Japan.

Referring to the four profiles of fathers in Portugal described by Wall (2014), in our study Masaki might be categorised as having the supported profile that represents fathers strongly supported by their partner or by a third party during the early part of the leave period. However, he started taking responsibility for all the housework and childcare after the mother returned to work, especially when his child got sick for a week during the period and he was on leave alone. In this sense, he should be described as the fundamental break profile in which fathers were weak helpers before the leave, but changed their attitude. The other five fathers were doing various kinds of the housework and care even before they took leave and took over most of the mother's roles. This small representation of the supported profile might be partly because of the small number of participants, but it is also likely that this is because of the small proportion of Japanese fathers who took this long parental leave on their own.

Difficulties in finding fathers who met the criteria also give some insights into the situation in Japan. Many of those to whom I was introduced and who were described as 'a father who took parental leave' did not meet the criteria, because they took it while their partner was on leave or not working. I found many interviews of fathers who took parental leave on the internet. However, closer examination shows that either mothers were also at home, or there is no explanation of his wife's situation. The policy change that enabled fathers to take leave while the mother was at home might not increase the number of fathers who are fully responsible for the care of a child unless a leave alone period follows.

Given the tiny proportion of fathers (fewer than $0.5 \%$ ) who took leave for a month or more, those who did so alone can be described as real pioneers. In many cases, taking leave seems to be a special event for fathers who are interested in becoming involved in the care of their child.

What we found from the interviews with six fathers on leave on their own is that, in Japan, they are still exceptional fathers with very special resources (including psychological ones such as a frontier spirit and an orientation towards gender equality, and practical ones such as the necessity of supporting their partner in continuing in full-time employment with a decent income). 
Acknowledgements I would like to thank the interviewed fathers for their cooperation, David W. Rycroft and Carole Pearce for English translation support.

\section{References}

Fujino-Kakinami, A. (2006). Child-care leave for male employees: from an analysis of qualitative data (in Japanese with English abstract). Kyoto Sangyo University Essays., 23, 161-178.

Matsuda, S. (2012). The reason why fathers leave take-up would not increase. Life Design Report, 201, 32-34.

Ministry of Health, Labour, and Welfare. (2012). Summary of the first longitudinal survey of newborns in the 21 st century (2010 cohort). http://www.mhlw.go.jp/toukei/saikin/hw/shusshoujib/01/dl/gaikyo01.pdf

Ministry of Health, Labour, and Welfare. (2013). Basic survey of gender equality in employment management 2012. http://www.mhlw.go.jp/toukei/list/dl/71-24e-003.pdf

Ministry of Health, Labour, and Welfare. (2014). Summary of the basic survey of gender equality in employment management 2013. http://www.mhlw.go.jp/toukei/list/dl/71-25r-03.pdf

Morita, M. (2011). Childcare leave of male workers and its significance in human resource management (in Japanese with English abstract). Bulletin of the Faculty of Sociology, Kansai University, 43(1), 147-163.

Morita, M. (2008). Chichi-oya ha ikuji-kyugyo wo toritainoka? [Do fathers want to take parental leave?]. In R. Yamato, S. Onode, \& K. Nachiko (Eds.), Otoko no ikuji, onna no ikuji: Kazoku shakaigaku karano apurochi, Showa-do, pp. 181-205.

National Institute of Population and Social Security Research. (2011). The fourteenth Japanese national fertility survey in 2010. Marriage process and fertility of Japanese married. highlights of the survey results on married couples. http://www.ipss.go.jp/site-ad/index_english/nfs14/ Nfs14_Couples_Eng.pdf

Nishioka, H., Yamauchi, M., Koyama, Y., Chitose, Y., Kamano, S., Suga, K., \& Hoshi, A. (2012). The family changes in contemporary Japan: Overview of the results of the Fourth National Survey on the Family in Japan. The Japanese Journal of Population, 10(1), 1-31.

Sato, H., \& Takeishi, E. (2004). Dansei no ikuji-kyugyo: Shain no niizu, kaisha no meritto [Parental leave by men: Workers' needs and benefits for companies]. Tokyo: Chuokoron-sha.

Takeishi, E. (2011). 'Chichi-oya no ikuji ni kansuru chousa kenkyu: Ikuji-kyugyo shutoku ni tsuite' kenkyu houkoku-sho [Report from 'the Research on child rearing by fathers: take-up of parental leave'], Tokyo: Kodomo mirai zaidan.

Wall, K. (2014). Fathers on leave alone: Does it make a difference to their lives? Fathering: A Journal of Theory, Research, and Practice about Men as Fathers, 12(2), 196-210.

Open Access This chapter is licensed under the terms of the Creative Commons AttributionNonCommercial 2.5 License (http://creativecommons.org/licenses/by-nc/2.5/), which permits any noncommercial use, sharing, adaptation, distribution and reproduction in any medium or format, as long as you give appropriate credit to the original author(s) and the source, provide a link to the Creative Commons license and indicate if changes were made.

The images or other third party material in this chapter are included in the chapter's Creative Commons license, unless indicated otherwise in a credit line to the material. If material is not included in the chapter's Creative Commons license and your intended use is not permitted by statutory regulation or exceeds the permitted use, you will need to obtain permission directly from the copyright holder. 